\title{
A MODIFIED MODEL TO ESTIMATE BUILDING RENTAL MULTIPIERS ACCOUNTING FOR ADVALOREM OPERATING EXPENSES
}

\author{
S.A. Smolyak, prof. \\ Central Economics and Mathematics Institute (CEMI) \\ Russia Academy of Science (RAS) \\ e-mail: smolyak1@yandex.ru
}

Abstract

To develop ideas on building element valuation contained in the first article on the subject published in REMV, we propose an elaboration of the approach accounting for ad valorem expenses incidental to property management, such as land taxes, income/capital gains tax, and insurance premium costs; all such costs, being of an ad valorem nature in the first instance, cause circularity in the logic of the model, which, however, is not intractable under the proposed approach. The resulting formulas for carrying out practical estimation of building rental multipliers and, in consequence, of building values, turn out to be somewhat modified, and we demonstrate the sensitivity of the developed approach to the impact of these ad valorem factors. On the other hand, it is demonstrated that (accounting for) building depreciation charges, which should seemingly be included among the considered ad valorem factors, cancel out and do not have any impact on the resulting estimates. However, treating the depreciation of buildings in quantifiable economic terms as a reduction in derivable operating benefits over time (instead of mere physical indications, such as age), we also demonstrate that the approach has implications for estimating the economic service lives of buildings and can be practical when used in conjunction with the market-related approach to valuation - from which the requisite model inputs can be extracted as shown in the final part of the paper.

Keywords: market value, valuation, buildings, income, rental multiplier, land, taxes, ad valorem expenditures, discounting.

JEL Classification: R30, D03, D40

Citation: Smolyak S.A., 2016, A Modified Model to Estimate Building Rental Multipiers Accounting for Advalorem Operating Expenses, Real Estate Management and Valuation, Vol. 24, No. 3, pp. 16-26.

DOI: 10.1515/remav-2016-0018

\section{Introduction: overview of the underlying principles of the original model}

This article is written as a continuation/elaboration of the original paper "A model to decompose Property Rental Multipliers with regard to the division between land and building elements" (SMOLYAK 2016), in which a model for commercial building valuation was presented based on the unorthodox use of the DCF method. Unlike in other methods for determining the market value of a building element, the following factors were explicitly accounted for in the model:

- Benefits from the use of the building vary over time: they increase under the influence of inflation and are reduced due to physical and functional depreciation.

- The remaining service life of the building is determined not only by its technical condition. It also depends on the value of the land element beneath the building, and how rapidly it undergoes change.

The model proposed in the referred article was based on the principle of "stable dependencies" which, in fact, is commonly used by valuers. According to this principle, mathematical and statistical dependencies that make market valuation contingent on various factors identified by the actual data 
for some (not too extensive) period of time preceding the valuation date, can be considered valid for a short period after that date. It is this principle that allows valuations of property to be carried out at a certain date using market information relating to an earlier period.

In assessing the market value under the proposed model, the principle of stable dependencies is complemented by reliance on a non-orthodox version of the DCF method, which can be expressed as follows:

The market value of the subject property at the measurement date is determinable as the sum of the discounted (to the measurement date) net benefits arising from the highest and best use of the property over an infinitesimal interval of time, plus the market value of the property at the end of this interval (also on a discounted basis for this interval).

This application is unorthodox in the sense that, if applied to infinitesimal periods, it allows for linking market values of the property at proximate time points and, subsequently, applying differential calculus to obtain an equation describing the dynamics of these values.

As was shown in the referenced original Paper, this technique allows us to offer formulas to estimate the market value of the building that do not require long-term forecasting of cash flows from building use.

At the same time, these formulas were derived with the use of rather simplistic assumptions.

In particular, two important factors were left out of consideration in them:

1) Entering into expenses associated with the use of the property are also costs the amount of which depends on the value of subject property, which in itself requires evaluation in the problem (the so-called issue of "circularity"). Because of this, the ratio of pre-tax to after-tax income from the use of the building shows a change which fails to be reflected in the originally proposed model.

2) Part of the income from the use of the property is appropriated by the state in the form of taxes (including income/profit and property taxes).

This article aims to provide a refined (modified) building valuation model, which considers these additional aspects.

Until now, we have assumed that, when undertaking a property valuation, the valuer is able to assess the operating costs associated with the use of the building. At the same time, operating expenses include property taxes, the amount of which depends, firstly, on the valuation of the property (in case of ad valorem property taxation regimes, which we consider in the paper. To fix this oversimplification, we need to subdivide operating expenses, allocating those types of costs which depend on the value of land and buildings to a separate category - that of "ad valorem costs". Property taxes have an important place among these ad valorem costs. These taxes vary between different countries. In some jurisdictions, they are levied on the basis of the taxable value of property as a whole (building + land elements), and in other jurisdictions - differentiated tax rates are in place to provide for separate taxation of land and building(s). Ad valorem costs also include other costs, the amount of which is linked with the value of the property, for example, insurance costs.

\section{Accounting for the impact of ad valorem expenses}

We consider an (overall) property, i.e. a land parcel with a building sited on it. The market value of the land - $L$, is assumed known, as per assumptions of the original paper, and the market value of the building - C, requires valuation. The use of the building brings a certain income to its owner, but also involves the incurrence of certain operating expenses. At the same time, operating expenses include property taxes, the amount of which is dependent on the market value of the property being valued. We shall account separately for such ad valorem expenses.

The basis of valuation of income-producing properties is grounded in the flow of benefits from its most efficient (i.e. highest and best) use.

We shall distinguish between four types of benefits:

- Gross benefits - are the proceeds of a building owner (for example, from putting a property up for lease).

- Operating benefits (hereinafter - OBs) - are understood to mean gross benefits less operating costs incurred by the owner. But, in our instance, depreciation charges, land tax and other ad 
valorem expenses are isolated from such costs and will be accounted for separately ${ }^{1}$. It appears that $O B$ s calculated on this basis will have a greater claim to being called "pre-tax" OBs and be better suited for collecting and analyzing data related to the incomes and expenses of property owners.

- Net operating benefits (NOB) - are operating benefits less property taxes and other ad valorem expenses.

- Net benefits (NB) - are net operating benefits, net of income taxes.

The ratio of land value to the amount of the $O B s, p=L / B$, shall be called the Payback Period for Land (PPL).

Also to be noted is that the value of a property assessed for the purposes of insurance and taxation may, in practice, differ from its market value, although both values should bear a close relationship to each other. In view of this, the model we develop should assume that ad valorem expenses per unit of time associated with the building are proportional by a certain fraction $m$ to the market value of the building $C$, while ad valorem levies associated with the land stand at a certain fraction $q$ to the market value of the land $L$.

With these preliminaries, let us now move on to the construction of the modified model itself.

We shall consider a market in which a number of similar buildings that yield different amounts of operating benefits - $B$, and are located on land parcels with different values are traded. At the same time, we shall assume that, for the given category of buildings in the proximity to the valuation date:

1) the value of land parcels changes at the same (known) rate $j$, not exceeding the discount rate,

2) OBs grow (change) at the same (known) rate $i$ (also not exceeding the discount rate),

3) the rental multiplier $R M$ (i.e. the ratio of building element value to the operating benefits from its use, $C / B$ ) depends on the Payback Period for Land $(p)$, i.e. is defined by the formula $R M=f(p)$ with the specification of the function $f$ remaining unknown.

Hence, it follows that:

$$
C=B f(p)=B f\left(\frac{L}{B}\right)
$$

It is important to note that, in view of the "stable dependencies principle", such a dependency is assumed to hold not only as at the valuation date, but also in the neighborhood of that date.

Consider one of such properties on the market with an OBs rate equal to $B$, a building value equal to $C$, and a land value equal to $L$. As such, the $P P L$ value for such property would be equal to $p=L / B$. Assuming that the use of the building for its intended purpose over the (mathematically) infinitesimal period of time $d t$ is economically justifiable, the values for $B, L, p$, and $C$ would sustain a change by the end of the period. It is possible to determine the new values of these variables (we make use of the tilde (" " - mark) to denote such new values) with an accuracy up to infinitesimals of a higher order, according to the following formulas based on assumptions a)-c) $)^{2}$ :

$$
\begin{gathered}
\tilde{B}=(1+i d t) B, \quad \tilde{L}=(1+j d t) L=(1+j d t) B p, \\
\tilde{p}=\frac{\tilde{L}}{\tilde{B}} \approx \frac{(1+j d t) B p}{(1+i d t) B} \approx p+(j-i) p d t, \\
\tilde{C}=\tilde{B} f(\tilde{p}) \approx(1+i d t) B\left[f(p)+f^{\prime}(p)(j-i) p d t\right] \approx \\
\approx C+i B f(p) d t+B f^{\prime}(p)(j-i) p d t .
\end{gathered}
$$

On the other hand, the value of the property as at the valuation date can be estimated by applying the DCF method and relying on pre-tax cash flow. In doing this, the appropriate pre-tax cash flow to use (i.e. cash flow before accounting for income taxes) shall be defined as operating benefits less ad valorem expenses (i.e. net operating benefits). Thus, in this case our alternative DCF application admits the following formulation:

We consider a potential buyer who acquires a property on the valuation date at its market value

\footnotetext{
${ }^{1}$ If the building owner acquires property using borrowed funds, we will not include loan amortization charges on account of such loans into building expenses (assuming that these would relate to the general operating activities of the owner, and not be apportioned to his management activities for specific buildings).

2 An upper stroke above the function sign $\left(f^{\prime}\right)$ denotes the derivative of the function here.
} 
$C+L$, puts it to a rational use over a short period of time $d t$, and then disposes of the property at a different market value $\tilde{C}+\tilde{L}$.

The value of the building shall be determined consistent with the flow of benefits to such a buyer upon him/her purchasing the property. Thus, these benefits would amount to:

1. Purchaser's $O B$ s over the $d t$ period would amount to $B d t$, land taxes paid by him - $q L d t$, while his other ad valorem costs associated with the building would be $-m C d t$ (since the residual value of the property, forming the basis of, let us say, insurance premia, is set equal to its initial purchasing value). Thus, net operating benefits shall be equal to:

$$
N O B=(B-q L-m C) d t=[1-q p-m f(p)] B d t .
$$

2. Over the mentioned period, the purchaser would also have to incur depreciation charges on his building, the amount of which, $A d t$, would be proportional to the duration of the period (we shall see further down that the particular amount of $A$ has no impact on the final result). Thus, the taxable income from the purchaser's operating activities associated with the use of the building would be NOB- Adt.

3. Purchaser's reversion (i.e. proceeds from the resale of property at the end of the period) would amount to $\tilde{C}+\tilde{L}$. Taxable income due to reversion (i.e. reversionary income subject to capital gains tax), according to our assumptions, would amount to this income less the value of initial investment in the land - $L$, and building elements (the latter reduced by the amount of the depreciation charge $)^{3}, C-A d t$, that is the reversionary taxable income, would equal: $\tilde{C}+\tilde{L}-(C+L-A d t)$.

Thus, the total amount of taxable income would come to be equal to:

$$
N O B-A d t+\tilde{C}+\tilde{L}-(C+L-A d t)=N O B+\tilde{C}-C+\tilde{L}-L,
$$

while the respective amount of profit/income tax to be levied over $d t$ time period would amount to ${ }^{4}$ : $P T=n[N O B+\tilde{C}-C+\tilde{L}-L]$. As can be seen, the tax is indeed independent of the amount of the depreciation charge and, in view of the formulas (2), has the same order of magnitude as $d t$.

Let us now apply our DCF method in its unorthodox framing expressed at the outset of the article (in the bold frame) to the derived benefits and expense stream. For this, we shall make beginning-ofperiod attribution for incomes and expenses of $d t$ order of smallness (i.e. we shall attribute NOB to the beginning of the period), and will use nominal after-tax rate - $\rho$ for discounting the rest:

$$
\begin{gathered}
C+L=N O B+(1-\rho d t)(\tilde{C}+\tilde{L}-P T) \approx N O B-n[N O B+\tilde{C}-C+\tilde{L}-L]+ \\
+(1-r d t)(\tilde{C}+\tilde{L})=(1-n) N O B-n(\tilde{C}-C+\tilde{L}-L)+(1-\rho d t)(\tilde{C}+\tilde{L}) \approx \\
\approx(1-n) N O B-n(\tilde{C}-C+\tilde{L}-L)+(1-\rho d t)(C+L)+(\tilde{C}-C+\tilde{L}-L)= \\
=(1-n)[N O B+\tilde{C}-C+\tilde{L}-L]+C+L-\rho(C+L) d t
\end{gathered}
$$

Substituting expressions from (2) and (3), this equality can be expressed as follows (with an accuracy up to higher-order infinitesimals):

$$
\begin{gathered}
0=(1-n)\left\{[1-q p-m f(p)] B d t+i B f(p) d t+B f^{\prime}(p)(j-i) p d t+B p j d t\right\}- \\
-\rho[B f(p)+B p] d t
\end{gathered}
$$

Dividing both parts of the expression by $(1-n) B d t$ and substituting new notation $r=\rho /(1-n)$, would

\footnotetext{
3 Provided that the residual (i.e. depreciated) book value of the building element is used as a basis for calculating capital gains tax on the building.

4 We assume that profit/income and capital gains tax are levied at the same rate - as is the case in some jurisdictions.
} 
yield the following:

$$
(j-i) p f^{\prime}(p)-(r+m-i) f(p)-(r+q-j) p+1=0 .
$$

It shall be noticed that $r$ is the ratio of the after-tax nominal discount rate to the tax adjuster (1-n), that is to say $r$ is the pre-tax nominal discount rate, which is the rate format usually used in the context of property and business valuations.

Solutions to Equation (5) would vary depending on the ratio between the rate of growth for OBs (i) and the rate of growth for the value of land $(j)$. Here, as in the Section 5 of the original paper, three situations can be considered:

Case 1. $i<j$. Let us introduce the following notation:

$$
s=\frac{1}{r+q-j} ; \quad \alpha=\frac{r+m-i}{j-i}
$$

Here, the value of $s$ would reflect the limit of the payback period for land; when reached, the use of the building for its intended purpose ceases to be economically expedient. This will be demonstrated by invoking an argument similar to the one used in Section 5 of the original paper, namely we shall consider a building, the use of which under its intended purpose has already ceased to be appropriate, i.e. a building that has zero value. Then, the value of such a property would be greater than the sum of the benefits arising from its use over the period $d t$ and the value of the property at the end of this period (suitably discounted). In other words, the left-hand side part of (4) would become greater than its right-hand side:

$$
C+L \geq(1-n)[N O B+\tilde{C}-C+\tilde{L}-L]+C+L-\rho(C+L) d t .
$$

But the value of the building under consideration equals zero as at the valuation date, and will likewise remain the same at the conclusion of the period, so that $C=\tilde{C}=0$. Additionally, $\tilde{L}=(1+j d t) L$; therefore, having regard to Formula (3), the above inequality will assume the following form:

$$
L \geq(1-n)(B-q L+j L) d t+L-\rho L d t
$$

It is easy to see that this inequality will only hold if $0 \geq B-(q-j) L-r L$, that is when $p \leq 1 /(r+q-j)=s$. Therefore, the solution to (5) must become zero at $L=B s$. By utilizing conventional methods for solving Equation (5) given this boundary condition, the following formulas can be derived, which coincide with the corresponding formulas presented in the original article for $m=q=n=0$ :

$$
\begin{aligned}
& R M=f(p)=\frac{1}{r+m-i}\left\{1-\frac{\alpha}{\alpha-1}\left(\frac{p}{s}\right)+\frac{1}{\alpha-1}\left(\frac{p}{s}\right)^{\alpha}\right\} . \\
& C=B f(p)=\frac{B}{r+m-i}\left\{1-\frac{\alpha}{\alpha-1}\left(\frac{L}{B s}\right)+\frac{1}{\alpha-1}\left(\frac{L}{B s}\right)^{\alpha}\right\} .
\end{aligned}
$$

We can see that the inclusion of ad valorem expenses does not affect the general character of the rent multiplier's functional association with $P P L$, but alters the values for parameters $s$ and $\alpha$ in this relationship.

It shall be noticed that the derived formula for building valuation, unlike other traditionally employed DCF-based formulas, neither calls for long-term forecasting of net incomes, nor requires an assessment of the residual service life of the building. At the same time, it provides for a more detailed adequate capture of the impact of underlying land values, taxes and ad valorem expenses on the value of subject buildings. 
Fig. 3 graphs the resulting dependency of the rent multiplier on PPL as per formula (16), given a (pre-tax) discount rate of $13.5 \%$ per annum, an annual $7 \%$ growth rate for land value, and an annual $3 \%$ growth rate in OBs. The dotted line represents calculations carried out excluding ad valorem costs ( $m=q=0)$, while the solid line corresponds to the values of $m=0.032, q=0.01$. As in the original article, the graphs charting the dependency of RM on PPL become tangent to the horizontal axis.

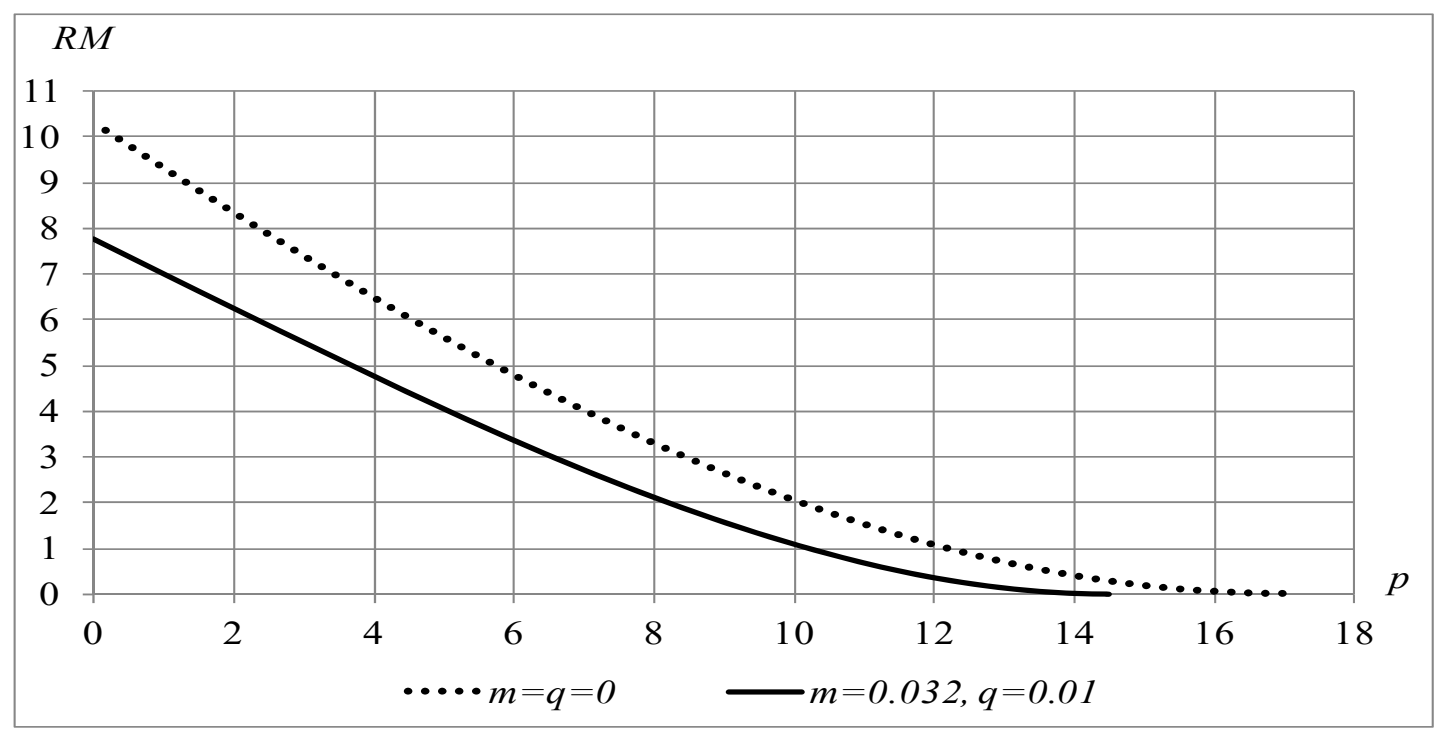

Fig. 1. The functional dependence of the rent multiplier on $P P L$ for two cases in which ad valorem costs are identified and disregarded. Source: own study.

We will now introduce examples with inputs identical to examples 1-5 of the original Paper ${ }^{5}$ to estimate the value of rental multipliers for the buildings given ad valorem expense rates of $m=0.032$ and $q=0.01$ as a new detail, and to see how the obtained results will differ from the ones calculated in the original paper. The following rental multiplier (RM) values result for these ad valorem input specifications (see Table 1).

Table 1

Rental multiplier results for original and ad valorem expense-adjusted examples

\begin{tabular}{llllll}
\hline Examples: & 1 & 2 & 3 & 4 & 5 \\
\hline $\begin{array}{l}\text { Values for rental multipliers (RMs) } \\
\text { derived in the original example: } \\
\mathrm{m}=\mathrm{q}=0\end{array}$ & 8.33 & 6.47 & 7.31 & 10.85 & 7.09 \\
\hline $\begin{array}{l}\text { RM Results incorporating specification } \\
\text { for new ad valorem inputs: } \\
\begin{array}{l}m=0.032, q=0.0(\mathrm{~s})\end{array}\end{array}$ & 6.24 & 4.76 & 5.37 & 7.59 & 5.46 \\
\hline
\end{tabular}

Source: own study.

It would appear from Fig. 1 and the Table above that a separate treatment of ad valorem expenses brings about a reduction in the value of the buildings. However, such a conclusion is unjustifiable.

\footnotetext{
5 These examples for rental multiplier (RM) calculation (realized using Formulas (9) and (10) of the original Paper), being:

Example 1. With the value of land being $120 \mathrm{CU}$ (currency units), the growth rate in land value - 7\% per year, the operating income from the use of the building (its annual representation, expressed in prices effective as at the valuation date) - $60 \mathrm{CU}$, and the growth rate for the operating income - 3\% per year.

Example 2. In contrast to Example 1, the value of the land is assumed to be twice as high - $240 \mathrm{CU}$.

Example 3. Assuming that, in contrast to the specifications in Example 2, the growth rate in the value of the land (j) is higher - at $10 \%$ per year.

Example 4. To find out what effect a possible inaccuracy in establishing the OB growth rates (i) may have on the valuation presented in Example 1, suppose, for example, that the growth rate is set not at 3\%, but at $5 \%$ per year. Example 5. To establish the extent of the influence a wrongly estimated discount rate may have on the valuation result in Example 1 suppose, for example, that the rate is not $13.5 \%$, but $15 \%$.
} 
The fact of the matter is that such treatment changes the composition of operating benefits, and increases their magnitude (exactly by the amount of ad valorem expenses); consequently, PPLS are reduced. Therefore, the valuation results obtainable with and without seperately accounting for ad valorem expenses, even at the same values for $O B s$, are not directly comparable.

Case 2. $i=j$. Here, Equation (5) will assume the following form:

$$
-(r+m-j) f(p)+1-(r+q-j) p=0 .
$$

From which it immediately follows that:

$$
R M=f(p)=\frac{1}{r+m-j}\left(1-\frac{p}{s}\right), \quad C=B f(p)=\frac{1}{r+m-j}\left(B-\frac{L}{s}\right) .
$$

These formulas stem from formulas (7)-(8) at $i \rightarrow j$, that is, at $\rightarrow \infty$. Note that these formulas are only valid upon producing a non-negative value for the building. This condition is observed only when PPL does not exceed $s=1 /(r+q-j)$. Otherwise the value of buildings drops to zero.

Case 3. $i>j$. It may seem that a solution to this situation can be provided by Formulas (7) and (8); however, this is not the case. In fact, the value of $\alpha$ will then become negative according to Formula (6), and Function (7) will have a discontinuity at $p=0$ breakpoint. A detailed analysis indicates that a continuous solution to equation (5) can only be provided by

$$
R M=f(p)=\frac{1}{r+m-i}-\frac{r+q-j}{r+m-j} p, \quad C=\frac{B}{r+m-i}-\frac{r+q-j}{r+m-j} L .
$$

It can easily be shown that, given $i=j$, Formulas (10) and (9) will match each other. The value of a building estimated according to Formula (10) will only be positive if $p<s=1 /(r+q-j)$.

Analytical corollary: It can be proved that, accounting for ad valorem expenses for $i=j$ and $i>j$, results in the very same formulas which were obtained in the original paper where such expenses were disregarded. A very important finding has been demonstrated here: if applied correctly, our alternative version of the DCF technique yields the same estimation formulas, regardless of whether or not income tax is accounted for, and the alternative DCF technique yields the same valuation formulas provided that the ratio of "after-tax" and "pre-tax" discount rates is proportioned according to the "tax adjuster".

Thus, accounting for income/profit tax in these instances does not change the results of the estimates obtained in the examples in Section 5 of the original Paper.

\section{Estimation of the remaining economic service life of a building}

As demonstrated in the previous sections, the developed model shows there is some sensitivity in building value to the OBs growth rate, so forecasts characterized by a greater accuracy of OBs estimates are desirable. The accuracy of the obtained results can be greatly enhanced by reliance on additional information. The following considerations may be helpful.

It would seem that the growth rate for OBs can be established by comparing average rental rates as at the valuation date in general, with those occurring a year earlier. However, such a comparison would be invalid, even given a representative sample of buildings. Suppose that we are in possession of data on rental rates for similar buildings, those newly commissioned and those aged 10, 20, $30 \ldots$ years; what we would then be doing is essentially deriving averages for the ratios of current rental rates to last year's rental rates in respect to buildings in the continuum of 0 years (newly commissioned), 10 years, 20 years, etc.

However, what we need to know is how rental rates change in the same building as it ages. To do so, we need to compare:

- last year's rate in a building which was newly commissioned a year ago vis-a-vis the current rate holding for the same building (which has aged one year as at the valuation date),

- the previous year's rate in a building aged 10 years to the current rate effective for a building 11 years of age.

The difference resulting from the wrong choice of a default approach may, of course, not be particularly pronounced, but the choice of an appropriate comparative method will tend to reduce the 
actual and forecasted short-term growth rates for rent. A similar problem would arise if one were to examine the amount of the owner's expenses. Here too, one would need to match last year's expenses for buildings of different ages with current expenses for buildings a year older.

The above considerations show that the process of estimating growth rates for OBs is prone to faulty specifications, which can significantly affect the integrity of the valuation results. This makes it necessary to introduce some cross-checks, ensuring that the obtained estimate of the building's value is consistent with existing "technical" information on the condition of the building. The remaining service life of the building may be used for this purpose, according to the method described below.

The analysis in the developed model is concerned with subject property over a short, incremental period of time. Therefore, it may seem beyond the scope of such analysis to determine how many years it will take for the continued use of the building to cease being efficient under its intended purpose. However, some inferences about the remaining service life (RSL) of the building can still be drawn from the model.

The general principle underlying the proposed evaluation procedure is explained as follows. Supposing that a period of one month has been chosen as the incremental period, let us consider Building 1, situated on land valued at $L_{1}$ and generating monthly benefits of $B_{1}$. These parameters will have changed in a month's time: the value of the land will become equal to $L_{2}$, and the monthly benefits $-B_{2}$. We will search the market for Building 2 with exactly the same attributes (i.e. situated on land valued at $L_{2}$ and generating monthly benefits of $B_{2}$ ). In this case, it would be natural to assume that the RSL of Building 1 will be one month longer than the respective RSL of Building 2. This implies that the RSLs of different buildings are somehow related to each other, such that for buildings with a PPL of more than $s$, the residual service life is zero, as building use for the intended purpose ceases to be appropriate. It turns out that these considerations are sufficient to evaluate the RSL of any building.

The items of real property in our market are characterized by the value of land $-L$, and the rate of OBs arising from the use of the buildings - $B$. This allows us to treat the RSL of the buildings as some yet unknown smooth function within these parameters, $T(L, B)$. Let us try to deduce this function explicitly.

We shall first consider a case where $i<j$.

In this regard, it will be noted that the parameters of the building will sustain a change over the brief incremental unit of time - $d t$ : the rate of OBs being generated by the building will grow by a factor of $(1+i d t)$, while a similar growth in the value of the land will be by $(1+j d t)$. Hence, the RSL of buildings with such altered parameters is equal to $T((1+j d t) L,(1+i d t) B)$. On the other hand, the resulting RSL is shortened by $d t$ compared to the subject building, and thus:

$$
T((1+j d t) L,(1+i d t) B)=T(L, B)-d t .
$$

Now note that with an accuracy up to infinitesimals of a higher order:

$$
T((1+j d t) L,(1+i d t) B) \approx T(L, B)+j L \frac{\partial T}{\partial L} d t+i B \frac{\partial T}{\partial B} d t,
$$

it follows that with an accuracy up to infinitesimals of a higher order:

$$
T(L, B)+j L \frac{\partial T}{\partial L} d t+i B \frac{\partial T}{\partial B} d t \approx T(L, B)-d t .
$$

It is easily seen that this equality is valid only if

$$
j L \frac{\partial T}{\partial L}+i B \frac{\partial T}{\partial B}=-1 .
$$

We have thus derived a partial differential equation for the unknown function $T$. Moreover, as shown above, the $T$ function drops to zero at $p=L / B=s$. Having regard to this boundary condition, a solution to Equation (20) is obtainable by conventional methods (see KAMKE 1948) for an example) and is as follows: 


$$
T=\frac{1}{j-i} \ln \frac{B s}{L}=\frac{1}{j-i} \ln \frac{s}{p} .
$$

If the RSLs calculated according to this formula substantially differ from those appearing credible on the basis of sound technical and economic criteria, this indicates an erroneous choice of the estimates for $i$ and $j$ rates.

Residual service lives, estimated in years, according to Formula (12) in the context of examples 1 to 5 (see footnote 6), given $r=0.1266$, first excluding ad valorem costs $(m=q=0)$ and then considering them $(m=0.032, q=0.01)$, are collated in the following table (Table 2$)$.

Table 2

Residual service lives (in years) resulting from the analysis of Examples 1-5

\begin{tabular}{llllll}
\hline Example & 1 & 2 & 3 & 4 & 5 \\
\hline$m=q=0$ & 56.1 & 37.9 & 31.6 & 113.3 & 50.8 \\
\hline$m=0.032, q=0.01$ & 52.0 & 33.8 & 27.4 & 105.0 & 47.4 \\
\hline
\end{tabular}

Source: own study.

In these examples, some questions may arise, either regarding the shorter service life as indicated by Example 3 or the seemingly excessive period of service life suggested by Example 4 . These durations would have to be cross-checked against the data on the remaining service life of the buildings estimated on the basis of technical criteria (the technical condition of the buildings and their continued use).

Let us now consider a case where $i=j$. Take a building with a PPL of less than $s$. Formula (12) would be valid for such a building, given $i<j$. Let us now increase the growth rate for OBs $i$, bringing it closer to $j$. The value of $s$ will remain unchanged in the process, while the remaining service life of the building, estimated according to Formula (12), will expand indefinitely. From this it follows that, at $i=j$, the remaining service life of a building becomes limitless. Quite naturally, in actuality there exist no buildings with a limitless remaining service life; however, this finding only implies that, given $i=j$, the remaining service lives of buildings are ultimately constrained not by economical, but by technical considerations. A detailed analysis also reveals that the same situation occurs when $i>j$.

\section{Applying the model in the context of a market approach to valuation}

As already noted, using the proposed models requires an estimate of the growth rates for the value of land $(j)$ and the benefits from the use of the buildings (i). A sales comparison (market) approach can be employed for that purpose. A general idea of how to apply it is demonstrated below in the context of a situation where $i<j$.

Suppose that the appraiser has information on four or more properties similar to the subject being valued. Specifically, the following is known for each comparable property $k$ : the value of the underlying land parcel $L_{k}$, the rate of benefits from the use of the building (in practical terms - the annual operating benefits) $B_{k}$ and the selling price of the building $C_{k}$. Having regard to these data, each comparable property can then be characterized by a payback period value for the land $p_{k}=L_{k} / B_{k}$ and a value of the rent multiplier $R M_{k}=C_{k} / B_{k}$. If the proposed model specifications are valid, the actual values of rent multipliers should be close to those estimated according to Formula (9). This means that the following approximate equality should hold for each $k$ :

$$
R M_{k} \approx \frac{1}{r+m-i}\left[1-\frac{\alpha}{\alpha-1}\left(\frac{p_{k}}{s}\right)+\frac{1}{\alpha-1}\left(\frac{p_{k}}{s}\right)^{\alpha}\right] .
$$

Keep in mind that the values for $s$ and $\alpha$ are associated with the parameter values $i$ and $j$ being sought according to equalities (6) $s=\frac{1}{r+q-j} ; \quad \alpha=\frac{r-i+m}{j-i}$. This association helps to express the values of $i$ and $j$, and $R M_{k}$ through those of $s$ and $\alpha$ : 


$$
\begin{gathered}
r-j=\frac{1}{s}-q, \quad r-i=\frac{1}{\alpha-1}\left[\alpha\left(\frac{1}{s}-q\right)+m\right] ; \\
R M_{k} \approx \frac{\frac{\alpha-1}{\alpha}-\left(\frac{p_{k}}{s}\right)+\frac{1}{\alpha}\left(\frac{p_{k}}{s}\right)^{\alpha}}{\frac{1}{s}-q+m} .
\end{gathered}
$$

It suffices to find parameter values for $s$ and $\alpha$ which would ensure that equalities (13) are observed with the maximum closeness of fit attainable. To achieve this, a solution to the following problem can be attempted using standard mathematical software packages:

$$
\sum_{k}\left\{\ln \left(R M_{k}\right)-\ln \left[\frac{\frac{\alpha-1}{\alpha}-\left(\frac{p_{k}}{s}\right)+\frac{1}{\alpha}\left(\frac{p_{k}}{s}\right)^{\alpha}}{\frac{1}{s}-q+m}\right]\right\}^{2} \Rightarrow \min
$$

Following this and assuming a specific pre-tax discount rate $-r$, an estimate for the rates $i$ and $j$ can be arrived at by using (14).

Below is an example to illustrate this. The annual pre-tax discount rate of $13.5 \%$ is used. It is assumed that $q=0.01$ and $m=0.032$. Data on seven comparable properties are given in the rows of the following table (Table 3).

Table 3

Market extraction example inputs

\begin{tabular}{llllllll}
\hline Property & 1 & 2 & 3 & 4 & 5 & 6 & 7 \\
\hline $\mathrm{B}$ & 60 & 36 & 40 & 50 & 60 & 65 & 80 \\
\hline $\mathrm{L}$ & 90 & 110 & 140 & 100 & 150 & 145 & 100 \\
\hline $\mathrm{C}$ & 400 & 200 & 225 & 340 & 360 & 430 & 589 \\
\hline $\mathrm{p}$ & 1.500 & 3.056 & 3.500 & 2.000 & 2.500 & 2.231 & 1.250 \\
\hline $\mathrm{RM}$ & 6.667 & 5.556 & 5.625 & 6.800 & 6.000 & 6.615 & 7.363 \\
\hline $\mathrm{RM}_{\mathrm{c}}$ & 6.970 & 5.790 & 5.456 & 6.589 & 6.210 & 6.414 & 7.160 \\
\hline
\end{tabular}

Source: own study.

Estimates developed according to the procedure suggested above indicate: $s=14.21$, and $\alpha=3.99$. These inputs used in conjunction with Formulas (14) suggest the following values: $i=0.0354$ and $j=0.0662$. Thus, the annual growth rate inferred for the value of land will be $6.85 \%$, while the annual rate of growth inferred for the operating benefits will be $3.60 \%$. Corresponding to these inferred values are the estimates for rent multipliers $\left(R M_{c}\right)$ shown in the bottom row of the table.

The obtained values for the discount and growth rates can now be used in connection with valuing other buildings.

\section{Conclusions}

In this paper, we have presented an extension to the building valuation model published in the previous edition of REMV $(\# 1,2016)$. This extension is in explicit consideration of ad valorem costs associated with the land and building elements, such as ad valorem land tax, income taxes, and insurance costs. As has been established in this paper, building valuations can be sensitive to these factors, except for instances when the assumed rates of change for the underlying land value and building income growth are equal $(i=j)$, or the latter exceeds the former $i>j$. As it happens, the proposed analytical framework also has a practical bearing on estimating optimal service lives for 
income-producing buildings.

\section{Acknowledgements}

This paper has been prepared under the sponsorship of a grant from The Appraisal Research Foundation (TARF). The author gratefully acknowledges the editorial assistance that he received from Dr. Michael Milgrim, for many years the editor of the International Valuation Standards, and from Andrey Artemenkov, MRICS. Without the assistance and support of these parties, it is unlikely that this paper would have been completed. Prof. Georgiy Mikerin and Mr. Igor Artemenkov, FRICS, have also, from the outset, given the author much appreciated encouragement in developing the ideas set forth in this paper.

\section{References}

Brown, R.G., 2005, Private Real Estate Investment: Data Analysis and Decision-Making, Elsevier Academic Press, pp. 82-90.

CONNER P., LIANG Y., 2005, Income and Cap Rate Effects on Property Appreciation, The Journal of Portfolio Management, Fall Special Issue.

GRIBOVSKY S.V., IVANOVA E.N., LvOv D.S., MEDVEDEVA O.E., 2003, Real Estate Valuation, Interreklama Publishers, Moscow, 2003 (in Russian).

IVSC, 2007, The International Valuation Standards 2007, The International Valuation Standards Council (IVSC). London 2007.

IAAO, 2003, The Standard on Automated Valuation Models. Approved in September 2003. www.iaao.org

KAMKE E., 1948, Differentialgleichungen, Lösungsmetoden und Lösungen, Band II, Partielle Differentialgleichungen erster Ordnung für eine gesuchte Funktion, Academische Verlagsgesellschaft, Leipzig, 1948 (in German).

LeE, H. S., CoRgel, J. B., SHIN, S., 2014, Estimating Net Operating Income Growth for Modeling U.S. Apartment Property Capitalization Rates. Journal of Real Estate Portfolio Management, 20(1), 67-78. Available on-line at: http://scholarship.sha.cornell.edu/articles/578/

LeYFER L.A., 2006, Direct Capitalization Method. Generalized Inwood Model, in Voprosy Otsenki, No. 3, 2006, pp. 15-20 (the article is also available online at http://www.labrate.ru/leifer/lev_leifer_article-model_inwood.htm) (in Russian).

SAyce S., Smith J., CoOper R., Venmore-Roland P., 2006, Real Estate Appraisal: From Value to Worth, Blackwell Publishing Ltd.

SMOLYAK S.A, 2008, Problems and Paradoxes in the Valuation of Machinery and Equipment, RIO MAOC, Moscow (in Russian).

SMOLYAK S.A., 2012, Models for Estimating Depreciation in Plants, Machinery, and Equipment: Analysis and Proposals, Journal of Property Tax Assessment \& Administration, Vol. 9, Issue 3, 2012. pp. 47-86.

SmOlyaK S. A., 2016, A Model to Decompose Property Rental Multipiers with Regard to the Division Between Land and Building Elements, Real Estate Management and Valuation, Vol. 24, No. 1, pp. 51-63.

WinNiCK L, 1952, Long-run Changes in the Valuation of Real Estate by Gross Rents, The Appraisal Journal, October 1952, pp. 484-498.

YISHENG YU, 2004, The Variation of Capitalization Rates Across Submarkets Within the Same Metropolitan Area, MIT Thesis Paper, http://dspace.mit.edu/bitstream/handle/1721.1/26731/59759952MIT.pdf?sequence=2. 